\title{
NOVAS EXPRESSÕES DA RELIGIOSIDADE: O QUE ELAS DIZEM SOBRE O SUJEITO EM SOCIEDADE HOJE
}

Anna Carolina Lo Bianco e Natália Vidal

Anna Carolina Lo Bianco

Professora do

Programa de

Pós-graduação em

Teoria Psicanalítica

da UFRJ. Bolsista do CNPq.

Natália Vidal

Doutoranda pelo

Programa de

Pós-graduação em

Teoria Psicanalítica

da UFRJ.
RESUMO: Nas últimas décadas surgiram novas expressões da religiosidade, manifestadas na proliferação das seitas engendradas numa dimensão de contrato e troca entre os fiéis e Deus. O artigo as compara com religiões tradicionais orientadas por um pacto que, ao contrário, mantém a referência à alteridade e a impossibilidade de um arbítrio frente aos desígnios de Deus. Para além das semelhanças que as unem - marcadas todas pela mesma busca da felicidade e do alívio para o mal-estar —, há diferenças acentuadas entre elas, que apontam para distintas configurações do laço social e do sujeito que delas é efeito.

Palavras-chave: Psicanálise, religiões, seitas, contrato, pacto.

ABSTRACT: New expressions of religiosity: what they say about subjectivity and society today. In the last decades new expressions of religiosity have arisen in the form of sects that entail a dimension of contract and exchange between the faithful and God. The present article compares them with traditional religions that are guided by the notion of a pact. The former keeps the reference to alterity and considers it impossible for people to arbitrate when facing God's will. In spite of their similitude — both sects and traditional religions are in search of happiness and relief from all kinds of discomfort in society — there are important differences between them pointing to diverse social bonds and hence different subjectivities.

Keywords: Psychoanalysis, religions, sects, contract, pact. 
Dasta uma olhada superficial na paisagem das principais cidades brasileiras,
para vermos a profusão de monumentais construções que abrigam um sem número de templos das mais variadas seitas. Surgidas, em geral, há pouco mais de duas décadas, indicam a ubiquidade do que podemos considerar novas expressões da religiosidade. Um olhar psicanalítico nos permite localizar no constante recurso às novas religiões e no sucesso que alcançam importante dimensão do tipo de vínculo que prevalece em nossa vida em sociedade.

Os cientistas sociais muitas vezes apontam para o poder organizador não desprezível destes movimentos (por exemplo, BOURDIEU, 1987). E não seria difícil, na comparação entre famílias que se afiliam às seitas e as que não o fazem, reconhecermos os efeitos positivos que o pertencimento a um grupo religioso frequentemente traz — sobretudo se pensamos em uma sociedade violenta, com os alarmantes índices de criminalidade - em especial homicídios como os que caracterizam nossas grandes cidades e suas populações. No entanto, acreditamos ver nas seitas efeitos apaziguadores que devem ser questionados, pois eles próprios, numa reviravolta não muito complexa, poderão ser encontrados quase sempre nas mesmas raízes dos fenômenos de violência. Hoje, grande parte dos conflitos em curso em diferentes partes do globo, a despeito de suas características e causas diversas, traz, entre estas últimas, motivos religiosos. A intolerância que neles têm lugar e seu correlato necessário - a violência — colocam em lados opostos até os adeptos de uma mesma religião.

Por isso, é interessante nos perguntarmos que subjetividades estão aí implicadas e como elas se articulam e sustentam os laços sociais que habitamos (LO BIANCO, 2007). A partir daí, podemos esboçar uma diferença relevante e uma inflexão marcante que se anunciam na vida social, refletindo-se nas instituições religiosas, que deixam então de ser consideradas apenas como uma resposta homogênea ao mal-estar e ao sofrimento com que nos defrontamos no dia a dia da cultura, para serem indicadores privilegiados das circunstâncias da própria vida cultural.

\section{A RELIGIÃO DO PACTO}

Ao criar o que foi considerado por Lacan (1967-1968/2001) o último mito moderno - Totem e tabu —, Freud (1913/1996) encontra os meios para falar da primeira forma de manifestação religiosa: o totemismo. Reconhece então a sua articulação necessária com configurações sociais e obrigações morais que constituem estas últimas.

Macho e forte, o pai era senhor da horda inteira, possuía todas as mulheres e exercia poder ilimitado e violento sobre os filhos, os quais acabaram por assassiná-lo (FREUD, 1913/1996). Entretanto, se o haviam odiado, veneravam-no 
como arquétipo e, em realidade, cada um deles queria ocupar o seu lugar. Ao parricídio sucedeu-se uma época durante a qual os irmãos lutavam entre si pela herança paterna; mas logo a lembrança da façanha que os havia livrado do estado de avassalamento em que se encontravam, assim como o sentimento que partilhavam acerca daquele tempo, levou-os finalmente a se unirem e a fazerem um pacto. Freud diz que: "nasce assim a primeira forma de organização social com renúncia do pulsional, reconhecimento de obrigações mútuas, estabelecimento de certas instituições que se declararam invioláveis (sagradas); vale dizer: os começos da Moral e do Direito" (1939/1996, p.79).

Desta maneira, estabeleceram-se o tabu do incesto e as leis da exogamia que sustentam a organização social (FREUD, 1913/1996).

É nesta configuração social regida pelo pacto que surge o totemismo - a primeira indicação da religião na história humana - , que encontra no totem a figura paterna e tem no banquete totêmico a expressão da ambivalência de sentimentos para com o pai assassinado e amado (idem). A força do mito de origem freudiano está nas condições que ele oferece para que venham a se alinhar no mesmo fio todas as religiões que então se sucederam (FREUD, 1939/1996). Elas sustentam, e ao mesmo tempo revelam, o pacto sobre o qual se erige a sociedade.

Por certo, o sujeito que resulta de tal arranjo social é propriamente sujeito ao pacto - portanto, às renúncias e limites que este institui (CZERMAK, 2013). Vale dizer, é aquele que deixa de resolver os conflitos com os meios da violência exercida por um só, ou por indivíduos, e se submete às instituições que expressam o poder de uma comunidade. As leis dessa nova associação determinam agora a medida em que cada um deve renunciar à liberdade individual de obter o seu bem a qualquer custo, para que venha a ser possível a convivência em sociedade, assim como, ao mesmo tempo, o exercício do desejo. Surge, nas boas hipóteses, o sujeito obrigado a afastar ou pelo menos a manter sob controle suas demandas, tendências e inclinações, que serão atendidas apenas até o ponto em que não se sobreponham ao bem comum (FREUD, 1929/1996).

A instauração dos monoteísmos, elegendo um deus-pai único que governa sem limitação, bem como o rito da comunhão, quando os fiéis incorporam a carne e o sangue de Jesus, são exemplos que repetem o sentido e o conteúdo do antigo banquete totêmico. Guardam a dimensão de partilha dos mesmos sentimentos, os quais garantem um lugar simbólico para o pai, entre os irmãos da horda (FREUD, 1939/1996).

Contudo, subjacente às obrigações morais e aos marcos institucionais que advém como herança das sociedades totêmicas, encontra-se um aspecto ainda mais fundamental e determinante para o sujeito: seu advento por referência ao desejo (LACAN, 1959-1960/1997). Ora, em Totem e Tabu (1913/1996) Freud chama 
a atenção para o caráter primordial e imperativo do desejo sobre a moral e as demais aquisições culturais. Nele vemos que não é o primeiro momento (assassinato do pai) que funda a Lei e as obrigações com o totem (caráter religioso), mas a identificação dos filhos a esta figura que se faz presente, num segundo momento, sob a forma de um sentimento de culpa. Foi diante desta ambivalência de sentimentos quanto ao pai, posto que cada filho aspirava tornar-se como ele, ocupar o seu lugar, no que ele era tão temido quanto invejado, que se recorreu ao pacto, como vimos, para a assunção de uma nova ordem (LACAN, 19691970/1992). Esta foi erigida sobre as interdições fundamentais a que se refere Freud (1913/1996) — dormir com a mãe e as irmãs — as quais, cabe salientar, guardavam uma intrincada relação com o desejo, pois diziam respeito às ações para as quais se podia identificar uma forte inclinação do sujeito (FREUD, 1913/1996). Se fosse facultado a cada irmão a livre satisfação dessa inclinação, o laço social seria inviável, pois entre eles travar-se-ia a mesma luta de vida ou morte que, os opondo ao pai, levara ao assassinato do mesmo. Para que a vida em comunidade fosse possível impôs-se a necessidade de renunciar aos objetos referidos acima (a mãe e as irmãs) e, com eles, a uma parcela significativa de sua vida sexual.

O que o mito totêmico situa, portanto, é a origem do laço social e da religião como fundado por um pacto que obedece a um imperativo de constituição do sujeito. Mas trata-se de um pacto ao qual subjaz a dívida simbólica com o pai, pois é ele que faz referência à livre satisfação como impossível ao mesmo tempo em que abre as vias para o exercício do desejo articulado à cultura (LACAN, 1959-1960/1986). Podemos pensar nessa dívida simbólica com o pai que o mito veicula - e que encontra expressão nas obrigações religiosas em relação ao totem — como uma referência à dimensão de perda que, como vimos, marca a constituição de cada sujeito quando se torna sujeito à vida em comunidade (MELMAN, 2011).

Contudo, conforme avançamos em direção à modernidade vemos a elisão dessa dimensão de pacto que havia sido, propriamente, o que viabilizara a vida em sociedade. O Estado Moderno, em suas bases contratuais, se assenta na ideia de um laço social fundado na livre iniciativa do sujeito, culminando, ademais, numa pretensa relação entre iguais. As restrições à livre satisfação do sujeito passam a ser creditadas à vontade geral dos cidadãos, elidindo, assim, que se devam a um imperativo de sua estrutura, com viemos demonstrando. E as instituições às quais a coletividade sacrifica (supostamente por vontade própria) essa satisfação, emergem como aquelas que poderiam garantir, em troca, a manutenção de um equilíbrio e harmonia mínimos quanto à convivência humana ou, ainda, restituir o que foi perdido. 
Não tendo por objetivo uma análise minuciosa do período, nos limitamos a apontar na passagem para a modernidade a ênfase no caráter consensual do contrato em oposição à assimetria que marca a ideia anterior de pacto. Trata-se de uma questão importante em nossa argumentação sobre as diferenças que separam as religiões tradicionais das novas seitas religiosas, pois, conforme referidas a uma ou outra dimensão - pacto ou contrato - cada uma delas nos dará notícias da dimensão ética em que se constitui o sujeito ou, ainda, de sua elisão. Ética, porque mais do que uma realidade biológica e/ou social, o sujeito da psicanálise é um sujeito dividido entre as exigências da cultura e a possibilidade de, submetendo-se a elas, ultrapassá-las no exercício do desejo. Ora, o laço social fundado no pacto confronta o sujeito com essa divisão, a qual lhe impõe uma perda — de gozo, de liberdade, de mestria — e um mal-estar inerentes à cultura, frutos do conflito que então se coloca entre suas disposições e a vida em sociedade. Este conflito decorre, também, da desigualdade inata e não eliminável entre os seres humanos, a qual constantemente gera tensões insolúveis que ainda assim terão que ser domadas ou reguladas (FREUD, 1933/1996). Sendo o mal-estar que atravessa a cultura irredutível, o pacto impõe ao sujeito uma perda irrevogável, para a qual não há nenhuma possibilidade de restituição. Ao passo que o laço social que enfatiza a dimensão do contrato, que identificamos como próprio às novas seitas religiosas, ao contrário, elidem a dimensão de pacto que atravessa suas instituições, assinalam a possibilidade de uma negociação que se buscará reparar.

Perde-se de vista, assim, o que o sujeito tem que pagar por sua entrada na cultura, ou seja, a dívida simbólica a que aludimos antes (LACAN, 1962-1963/2004). Tal dívida inscreve-se nas próprias origens desse significante - pacto - que a psicanálise identifica no fundamento da sociedade e na gênese dos principais sistemas religiosos. O referido significante tem sua origem no termo latino pactum — substantivo formado, por sua vez, a partir do verbo pangere, que significa “cravar, fixar, unir, determinar por acordo” (ETIMOLOGÍA DE PACTO, 2014). Este verbo se encontra na raiz etimológica de termos ainda hoje importantes por sua referência ao laço social. Entre eles destacamos o substantivo pax, ou seja, "vínculo e acordo bem travado que acaba com uma situação bélica”, de onde vêm termos como "paz", “pacífico”, "pacificar” e "pagar” (SIGNIFICADO E ORIGEM DE PACTO, 2014). Este último acabou por desenvolver em latim o valor de "acalmar a um credor", valor este que não possuía originalmente: pagar se dizia solvere (ETIMOLOGÍA DE PACTO, 2014).

O que a etimologia de "pacto" nos permite perceber é que, mesmo quando este termo designava um acordo, sua ênfase recaía na dimensão do laço (e do conflito que lhe é inerente). E, ainda que celebrado entre duas partes, pressupunha um terceiro - aquele a quem cabe pagar — da mesma forma como, no 
mito totêmico, a ordem social é formada por referência a um lugar de exceção - aquele do pai. Exclui-se, assim, a possibilidade de uma relação simétrica, de sustentação do laço social por uma ordem de equivalências. A referência a um registro terceiro obedece à própria estrutura da linguagem (LACAN, 19681969/2008), a qual, ela mesma, exclui a possibilidade de uma relação unívoca - portanto simétrica - entre seus elementos (por exemplo, entre significante e significado), dando lugar ao jogo metafórico e metonímico que lhe é próprio (LACAN, 1957-1958/1998). É esse mesmo deslizamento que nos permite perceber que, na evolução de seus significados, "pacto” veicula-se desde muito cedo à necessidade de um pagamento - seja da parte do sujeito, seja da coletividade. E, sendo a dívida a que nos referimos antes eminentemente simbólica, esse pagamento não encontra equivalência nos objetos da realidade. Fica assim excluída para qualquer religião fundada numa dimensão de pacto a possibilidade de uma negociação e/ou troca entre o sujeito e este lugar de exceção a que nos referimos acima (ou seja, entre o fiel e Deus) - é aqui que podemos falar de um sujeito e de seu desejo.

Por fim, em relação a este mito moderno de fundação das sociedades (FREUD, 1913/1996), ressaltamos que o pai que transmite a castração, as interdições nas vias do gozo, é o pai morto - aquele que acedeu a um estatuto simbólico (LACAN, 1957-1958/1998). A referência à morte aqui se impõe como fundamental. Ela abole a possibilidade de qualquer garantia na sustentação do laço social - no caso que debatemos, na relação do sujeito com a crença em uma de suas manifestações principais, a religião. Isso porque, se a sociedade pós-moderna busca se cercar de garantias (BARTOLOMEI, 2008) — seja em sua forma laica, com o saber, seja em sua forma religiosa (simbólica), recorrendo a Deus - , a morte se lhe interpõe como um limite. Limite tanto ao saber quanto ao Simbólico: não se sabe o que é a morte; para ela não há qualquer representação significante (FREUD, 1915/1996; LACAN, 1969-1970/1992). Seu caráter irredutível e enigmático é especialmente flagrante no lugar central que ocupa nas diferentes religiões, as quais, cada uma à sua maneira, buscam lhe dar um contorno, que só pode se sustentar no registro da crença — por isso mesmo, no de uma aposta a fundo perdido.

Aliás, quer se trate ou não da morte, é a crença que confere propriamente um lugar e uma força às diversas religiões, ao confrontar o sujeito com o que é posto pelo pacto: a referência à alteridade, a necessidade do desejo em fazê-la valer, a impossibilidade de uma garantia ou de um arbítrio frente aos desígnios de Deus na vida terrena. Veremos a partir de agora que a promessa de uma série de garantias ao sujeito, bem como a possibilidade de uma negociação, de uma relação simétrica com a alteridade, é um dos traços característicos dos movimentos religiosos recentes. Isso nos permitirá identificar uma lógica de 
funcionamento há muito em jogo em nossa sociedade e que a esfera religiosa, antes de a ter inaugurado, de fato a reproduz.

\section{AS SEITAS DOS CONTRATOS}

Serão os sujeitos ao pacto os mesmos que as seitas que vemos disseminadas por nossas comunidades evidenciam?

A questão de uma dívida simbólica que não encontra equivalente nos objetos da realidade, ou que se vê pretensamente reduzida aos mesmos, emerge de forma flagrante nos discursos de que se valem as seitas religiosas hoje. De um lado, vemos subsistir o discurso das religiões tradicionais, as quais, mesmo com seus anacronismos e preconceitos, sustentam o lugar de uma renúncia da parte do sujeito. De outro, um discurso que busca responder a esta dimensão de renúncia pelo serviço dos bens característico da lógica de mercado.

Estudos etnográficos cuidadosos como o de Giumbelli (2002) dão testemunho preciso desse discurso que nós mesmos cansamos de ver e ouvir nas diuturnas pregações dos pastores nas televisões. Tudo se passa na dimensão da troca: os fiéis pagam o dízimo para obter um milagre e são incentivados a cobrarem de Jesus a operação dos milagres pelos quais pagaram. Há mesmo relatos de templos em que se encontra na porta o aviso: "seu milagre garantido ou seu dinheiro de volta”.

A dimensão do pacto dá lugar agora a de um acordo regido pelos serviços dos bens. Tal acordo visa à satisfação completa das partes envolvidas, tomadas ademais em uma relação igualitária, horizontalizada. Trata-se aqui de alguém que se reivindica o suposto direito à igualdade em todas as esferas do cotidiano e de relações sociais que cada vez menos reconhecem um lugar às diferenças como as geracionais ou as sexuais. A referência a um terceiro, por relação ao qual, como vimos, a ordem se estabeleça e venha a se assentar na renúncia à satisfação imediata se vê, portanto, abolida. Na verdade, passa-se até mesmo a se exigir e contar com a fidelidade de Deus! Os adesivos nos carros comprovam que "Deus é fiel”.

O que aqui apontamos em relação às novas seitas traduz um processo há muito em jogo no laço social: é a modernidade que privilegia a ideia de um laço social atravessado pela dimensão contratual que ela, ademais, inaugura. Lacan (19671968/2001) fez referência a esse processo em seu seminário de 24 de janeiro de 1968. Dirigindo-se à sua audiência, ele não apenas denunciou o predomínio, em nossa época, de uma relação de troca na qual cada um supostamente receberia a parcela que acreditava ser a sua, como apontou seu caráter imaginário (especular). São abundantes nessa ocasião de seu seminário a presença de significantes tomados de empréstimo ao campo da economia, tais como "prestação de trocas", 
“esvazia bolsos”, “prestação de serviços”, significantes que passam a circunscrever o lugar do sujeito em termos mercantis (VIDAL, 2012).

Trata-se de uma relação análoga a que hoje podemos verificar em outros domínios da vida social, como, por exemplo, o Direito (idem). Cada vez mais o vemos trabalhar apenas para restituir ao sujeito, ratificando todas as suas demandas, ao mesmo tempo em que busca convertê-las em termos monetários. Hoje já é possível indenizar um filho pelo abandono afetivo por parte de seu pai, o que, para além de qualquer consideração de cunho moral, esconde a dimensão ética de se conferir à afetividade, ao desejo, um correlato em cifras (idem). Em ambos os casos — do Direito, das seitas religiosas — ao final de uma relação de troca perfeitamente constituída, almeja-se que o saldo da operação seja zero. Ou seja, que a cada um tenha sido concedida a sua parte. A consequência de um funcionamento social como este, contudo, não é aquele de um sujeito a quem é facultada uma vida mais plena, justa ou satisfatória. Ao contrário, posto que visa à completude, ele elide que a própria condição para que haja troca é que algo falte para o sujeito - dimensão do pacto e do desejo. Quanto a isso, afirma Lacan, “não se está de acordo” (1968-1969/2008), a conta não fecha, daí o caráter imaginário deste tipo de relação.

As religiões, se ainda podemos chamá-las assim, falam agora de uma sociedade onde vigoram as relações contratuais. De um sujeito que pagava por sua entrada na cultura - e que o faz a cada vez — nos deparamos com um sujeito (se é que há aí sujeito) que se porta como credor da cultura. É a época em que a Lei, o Direito, a religião, que se instalaram com o pacto, implicando obrigações morais e sacrifícios do prazer imediato, tendem a ser ultrapassados por uma "lógica do consumidor” (VIDAL, 2012). Há que se garantir a satisfação demandada pelo cliente que, afinal, tem sempre razão. As seitas se oferecem como prestadoras de serviços e bens, e vivem de fazer promessas de satisfação em curto prazo. Não estaríamos “nesse momento a que chegamos de civilização” (LACAN, 19681969/2008, p.31) frente a um sujeito que somente busca se exercer como um sujeito de direitos — um sujeito-consumidor?

Acreditamos, portanto, que para além das semelhanças que unem religiões tradicionais e movimentos religiosos recentes - marcados todos pela mesma busca da felicidade e do alívio para o mal-estar, ou seja, articulados todos para garantir os meios de apaziguamento do sofrimento — , há diferenças acentuadas entre ambos, que apontam para distintas configurações do laço social e do sujeito que delas é efeito.

Ainda uma última palavra para lembrarmos que, enquanto nas religiões tradicionais se trata da referência a um pai morto que, portanto, ocupa um lugar que é simbólico, encontramos agora nos membros das seitas uma convicção obcecada acerca do saber e da autoridade de um fundador encarnado que vem 
prometer a facilidade do encontro com os objetos da satisfação inadiável. De um assujeitamento ao simbólico, a esse "pai morto", passa-se assim à adesão a um líder (LO BIANCO, 2009). As consequências dessa afiliação cega, no mais, trazem-nos imediatamente à memória as cenas de horror já vistas no nazismo que marca o século XX, e marcará todos os outros depois dele.

Recebido em 2/7/2014. Aprovado em 30/7/2014.

\section{REFERÊNCIAS}

BARTOLOMEI, C. (2008) “La rétention de sûreté ou l'ilusion du risque zero par l'exclusion d'une poingnée de criminels", in CASTANET, H. Quelle liberté pour le sujet à l'époque de la folie quantitative?. Nantes: Plein Feux, p.105-111.

BOURDIEU, P. (1987) La distinction. Paris: Minuit.

CZERMAK, M. (2013) A porta de entrada e a clínica psicanalítica. Rio de Janeiro: Rio de Janeiro.

ETIMOLOGÍA DE PACTO. Disponível em: http:/etimologias.dechile. net/?pacto. Acesso em 10/6/2014

FREUD, S. (1996) Obras completas. Buenos Aires: Amorrortu.

(1913) “Tótem y tabú". v.XIII, p.1-163.

(1915) “De guerra y muerte. Temas de actualidad”. v.XIV, p.275-299.

(1929) "El malestar en la cultura”. v.XXI, p.57-140.

(1933) “Por que la guerra? (Einstein y Freud)”. v.XXII, p.179-186.

(1939) “Moisés y la religión monoteísta”. v.XXIII, p.1-132.

GIUMBELLI, E. (2002). O fim da religião. Rio de Janeiro: Attar.

LACAN, J. (1957-1958/1968) Le séminaire livre 5 — Les formations de l'inconscient. Paris: Seuil.

(1959-1960/1986) Le séminaire livre 7 - L'éthique de la psychanalyse.

Paris: Seuil.

(1962-1963/2004) Le séminaire livre X - L’angoisse. Paris: Seuil.

(1967-1968/2001) L’acte psychanalytic. Paris: Association Freudienne Internacionale.

. (1968-1969/2008) O seminário livro 16 - De um Outro ao outro. Rio de Janeiro: Jorge Zahar.

(1969-1970/1992) O seminário livro 17 - O avesso da psicanálise. Rio de Janeiro: Jorge Zahar.

LO BIANCO, A. C. (2007) O que a comparação entre a tradição religiosa e os novos movimentos religiosos nos ensina sobre o sujeito hoje?, Estudos de Psicologia (Natal), v.12, 129-132.

(2009) "Adesão ao líder ou submissão ao pai: a escolha do sujeito”, in COSTA, M. F., Psicanálise e laço social. Rio de Janeiro: 7 Letras, p.119-124.

MELMAN, C. (2011) A neurose obsessiva no divã de Lacan. Rio de Janeiro: Imago/ Tempo Freudiano. 
SIGNIFICADO E ORIGEM DE PACTO (2014) Disponível em: http:// www.significado.origem.de/significado.do?palavra=Pacto. Acesso em $10 / 6 / 2014$.

VIDAL, N. (2012) O real na letra da Lei: de uma escrita que dê lugar ao sujeito. Programa de Pós-graduação em Teoria Psicanalítica. Dissertação de Mestrado, UFRJ.

Anna Carolina Lo Bianco

aclobianco@uol.com.br

Natália Vidal

nvidal.ufrj@yahoo.com.br 